\title{
The Salt Wells of China
}

\section{Primitive Apparatus Used for Sinking Wells and Drawing Up the Brine}

\author{
By Robert G. Skerrett
}

$\mathrm{E}$ VEN though China does trail in the march of civilization, still her people give to the fair-minded Occidental ample warrant for admiring wonderment.

For centuries upon centuries those ingenious Orientals have applied with exceeding cleverness the fundamentals of physics and mechanics to the mastering of many difficult tasks. In some of their engineering achievements they have indubitably set the pace in much that is commonly deemed essentially modern among us. In none of her varied activities does China show this more strikingly than in the prosecution of certain departments of her very important salt industry.

Probably a thousand years or so before we bored in search of oil, gas, water, etc., the Chinese were drilling deep into the geological strata in their quest for greater supplies of indispensable salt. This was especially the case in the provinces remote from the sea where it was not possible for them to satisfy the demand by simply evaporating the ocean's abundant brine or similarly treating the outpourings of springs carrying a saline charge. To tap the subterranean store, the Chinese in the less favored districts have been obliged to bore to a depth of quite 4,000 feet; and to gain their goal they have had to penetrate through successive layers of interposed rock.

That they have succeeded in those undertakings is all the more remarkable when we contrast their primitive facilities with the instruments and apparatus which we now employ in kindred operations. True, we reach our objective quicker, but even so the driving of a well of comparable magnitude is an expensive job and we muster to its execution special tools skilfully fashioned and use drills made fit for their exacting work by the research of the metallurgist. Cables carefully manufactured for the purpose carry the load of the suspended metal implements, and the strands of these hawsers must be strong and elastic enough to bear the alternating stresses set up by the steel masses as they are lifted and dropped in pounding their way downward into the bowels of the earth.

And then, in order to handle the heavy weights involved, we have devised power-driven machinery capable of operating hour in and hour out, day after day, with a minimum of human supervision. Ruggedness and dependability are the outstanding characteristics of the apparatus, and the attendants always have at their disposal enough mechanical energy to minimize the burden laid upon their muscles. According to the method adopted, gas, oil, or steam may furnish the primary power; and the electric motor is now figuring in this field of industry. And how does the Chinaman attain his end ; and what are the aids which he depends upon?

But before describing his age-old appliances and practices it might be well to sketch in a general way the salt industry of

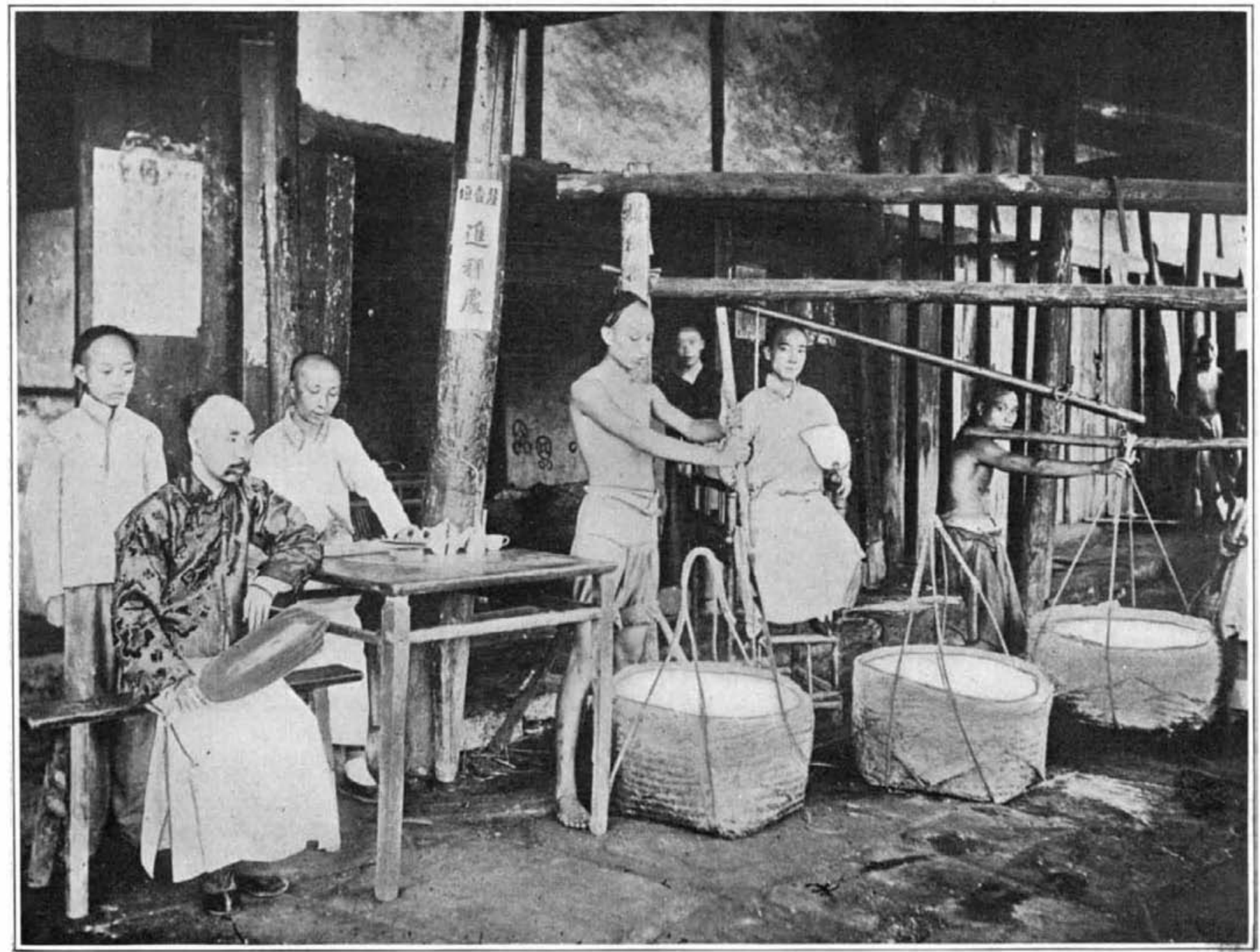

SALT BEING WEIGHED IN THE PRESENCE OF A GOVERNMENT OFFICIAL. THE SALT INDUSTRY IS HEAVILY TAXED 


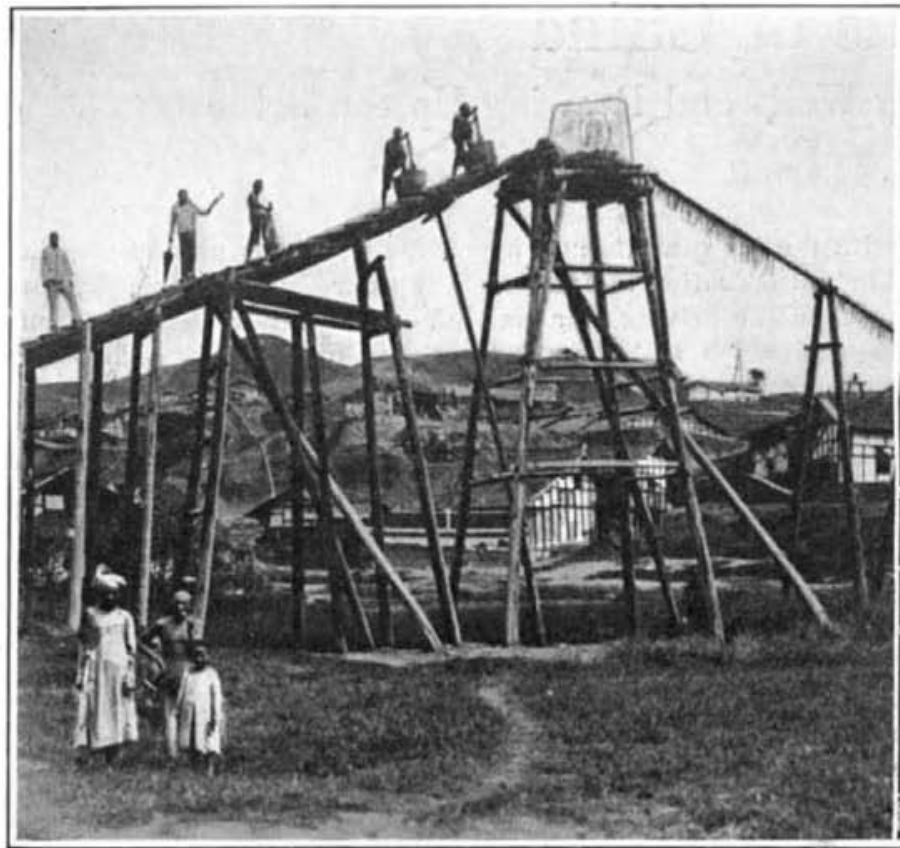

HAULING THE BRINE UP A TRESTLE FROM WHICH IT FLOWS THROUGH BAMBOO PIPES TO THE EVAPORATORS

China so that we may visualize its outstanding significance in the economic life of the nation. This will increase our astonishment at the Oriental reluctance to adopt up-to-date equipment in prosecuting the business. Normally, the domestic output of salt in the United States is in the neighborhood of $5,000,000$ tons and represents a value of approximately $\$ 12,-$ 000,000 annually; while in China, ordinarily, the tax alone each twelvemonth on salt is several times this sum. Plainly the industry is of monumental proportions.

China's salt gabelle is an institution of antiquity, and for many centuries the salt trade of that country has been a government monopoly. Indeed, the income derived in this way has more than once figured as a prime factor in guaranteeing loans made by foreign nations. This is not hard to understand if we bear in mind how the revenue was garnered. Before the establishment of the Chinese Republic the management of the salt tax was a subject on which little information was available. At that time China was divided, for purposes of administration, into eleven salt areas, seven of which produced sea salt, two lake salt, and two well salt; and these zones were subdivided into numerous districts-the object being to equalize in a measure the natural advantages or conditions prevalent in the several regions.

Then the government, besides levying a tax upon the salt, acted the while as middleman between the producer and the retailer, and not infrequently played the part of transportation agent and wholesaler; and the authorities did not hesitate to put upon the traffic all that it would bear. Salt has paid as many as forty-three different taxes during the various transactions between the producer and the ultimate consumer. These abuses have been modified since 1913, when the Chinese Republic secured an international loan of $\$ 125,000,000$ and offered the salt revenue as a security. Following that arrangement, the whole administration of the salt levy was reorganized, and the appreciation of silver has added greatly to the value of the income since 1914. The total revenues from the salt gabelle in 1916-the latest data available-amounted to $\$ 72,440,559$, Mexican. China jealously guards the whole salt trade, and strictly prohibits the importation of any of this material.

The two most interesting phases of the production of salt in China are those exemplified in the procedures followed, respectively, in the provinces of Hankow and Szechwan, where the brine is raised to the surface from considerable depths. In the Hankow district the annual output is about 15,000 tons

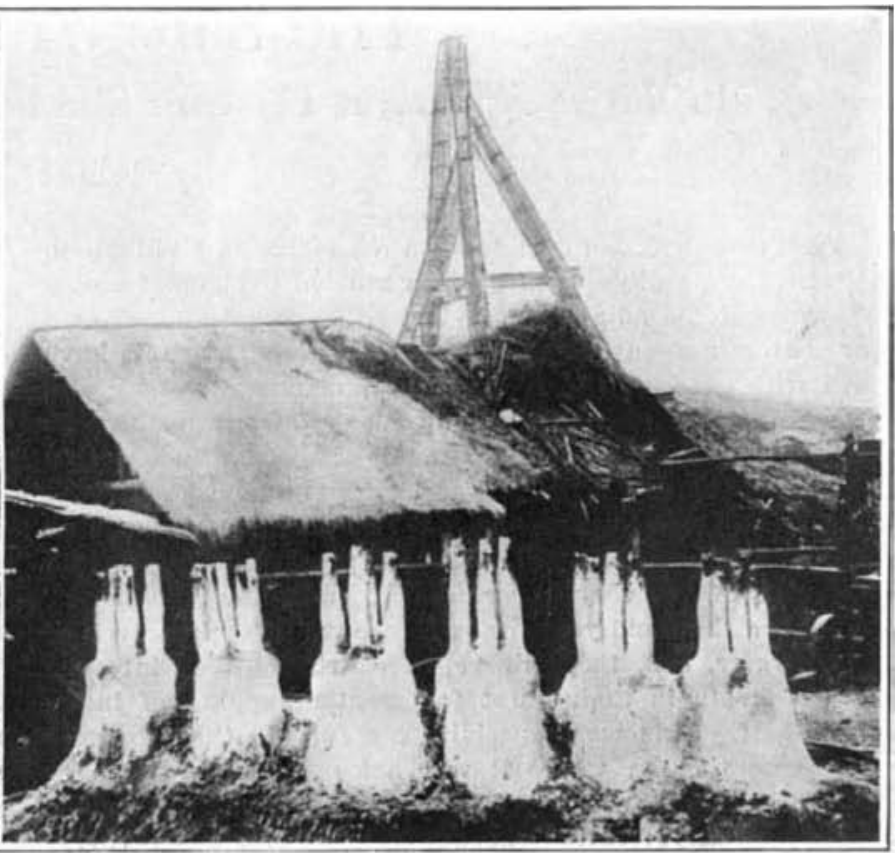

CEMENT-COVERED BAMBOO JETS OF A GAS WELL. THE GAS IS USED IN EVAPORATING WATER FROM THE BRINE

and this is obtained from a region where gypsum has been worked for quite two centuries. Salt, i.e., sodium chloride, is a fairly common accompaniment of gypsum deposits; and the salt-yielding layers in Hankow lie at depths ranging from 400 to 900 feet. The mineral is reached by sinking vertical shafts. The usual practice is to mine for gypsum for two or three years and then to close the pit for a period of twelve months, during which time brine is the outcome of natural leakage or is formed artificially by pouring water into the galleries, whence it flows down the slopes of the excavations which follow the dip of the gypsum.

Geologically, the salt is either held in the pores of the soft rock or it lies interspersed as sheets between the gypsum, and in breaking out the rock the salt is exposed so that the inundating water can penetrate and dissolve it. At the end of a twelvemonth sufficient brine accumulates to furnish work for from one to five months, after which the gypsum is again mined for an interval of two or more years. In this way the removal of gypsum and the leaching out of the salt go on alternately.

The brine is raised to the surface. by a simple windless and a rope to which wooden buckets are attached, and at the pit mouth the salty fluid is poured into nearby large wooden tanks sunk into the ground. From these reservoirs it is baled out into troughs, covered by mats, and these conduits convey it a distance of a few hundred yards to the furnaces, where the brine is boiled in iron pans to stimulate the evaporation of the water. These pans are disposed in batteries of from three to five to a furnace, and are set up beneath tiled sheds with open sides. The pans are made of boiler plate and are three feet in diameter and eighteen inches deep. The furnaces are built in pits lined with brick and are arranged so that the boiling pans are just above the ground level. The fuel is coal procured in the neighborhood of Hankow.

Coolies ladle the fresh brine into the caldrons, and as the fluid boils incessantly the water is rapidly vaporized. The salt precipitates as the density of the liquid increases, and at the proper stage the deposit is dipped out and dumped into split bamboo baskets. The salt thus produced is distributed to the consuming areas by small dealers who carry it about in two baskets slung at the end of a pole-the total load being around 100 pounds. The salt so manufactured is, snow white, very fine, crystalline and of good flavor, though slightly bitter. This is probably due to the presence of an excess of magnesium. Apart from using salt for seasoning his food, 
feeding livestock, etc., the Chinese employ it to preserve both meats and vegetables, and the nation at large requires immense quantities for this purpose.

Beyond question it is in the province of Szechwan that Chinese ingenuity shows at its best in the production of salt. There, fully 1,100 miles up the Yang-tze-Kiang from the sea, the Chinese have gone down anywhere from 2,000 to 4.000 feet in quest of brine; and in the course of a year they manufacture on an average substantially 385,000 tons of the commodity. Szechwan is able not only to supply the salt needs of its own millions of inhabitants but it sends annually into near-by provinces a matter of 82,000 tons of the stuff.

The leading producing centers of salt in the province of Szechwan are Tzuliuching and Wutungchiao. The wells

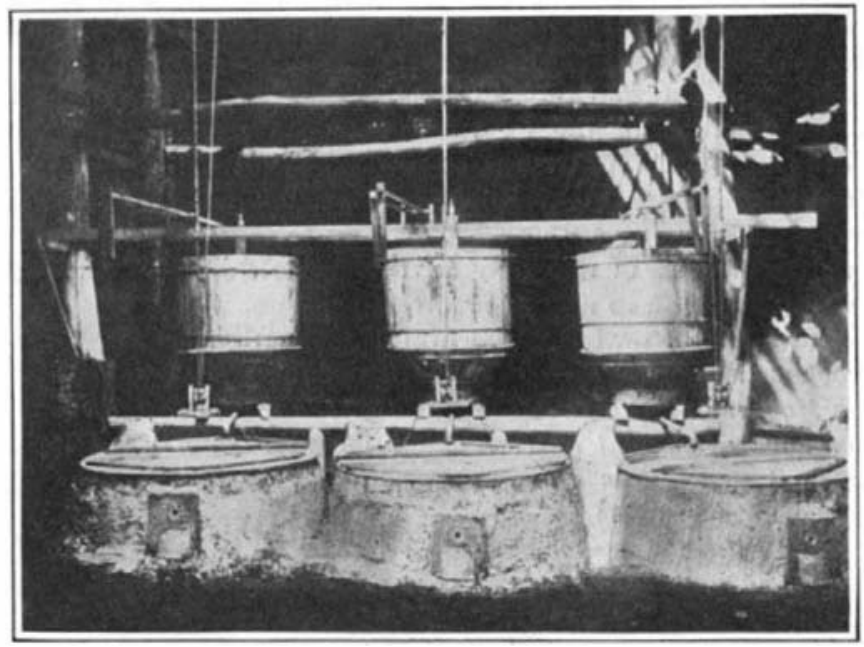

INTERIOR OF AN EVAPORATING HOUSE

around Tzuliuching are by far the most important, and are able to furnish about half of all of the salt obtained in the province. The boring of a well does not differ in principle from that commonly practiced in the search for oil and gas in this country, but the agencies relied upon are notably dissimilar. It is not hard to understand this when we grasp the somewhat isolated position of the province of Szechwan. It lies beyond the gorges and rapids of the Upper Yang-tze, and that waterway has for ages been the main route of commercial intercourse. Inasmuch as freight rates by that dangerous and tedious channel of trade are very high, and goods often have to be packed for some distance by man and beast, there was little inducement in the decades gone to introduce machinery which was sure to be too costly. Therefore, the Chinese owners of a salt concession wisely elected to depend as much as possible upon the brawn of the willing coolie who could be hired for a pittance.

To make sure that the bore of his well is vertical, the Chinaman has adopted a very effective means of steering his drill straight down at the start and of forcibly directing its course for a while thereafter. To this end it is customary for him to excavate a shaft to a depth of 200 feet, and in the center of this he sets upright and steadies by rock ballast a number of nicely hollowed-out tree trunks joined together to constitute a single wooden pipe. The upper portal of this guideway is protected by a limestone cap pierced with a 10-inch hole. With this installation complete the actual drilling of the well is begun.

Instead of the towering derricks characteristic of our oil fields, the Chinaman substitutes a low framework which supports a lever pivoted so that it may move in the vertical plane. At the short end of this pole is hung the drill rope with its pendant tools. Parallel with the longer arm of the lever are tẃ benches-one on either side, and upon these the men stand who operate the "jumping beam." By stepping on the lever it is depressed and the drill raised a foot in the shaft. Next, when the coolies hop off, the drill drops as the long arm of the lever rises. The number of men needful for this work is regulated by the load represented by the tools and the weight of the connecting line. The beam gang is divided into two squads, one on either bench, facing each other. The several men place their right feet on the lever, and at the word "go" all of them step with their left feet across and on to the neighboring bench, withdrawing the while their weight from the beam. Promptly all hands swing around and repeat this operation, and in the course of a minute the lever can thus be raised and dropped from ten to twenty times-the dirill hammering away under ground in unison. This interesting method of well drilling is illustrated in the frontispiece of this number.

The drill is generally a 12-foot bar. of iron having a cutting face with a spread of 4 inches, and the tool weighs about 200 pounds. Above this drill is suspended another bar encased in bamboo, and its function is to add to the blow of the descending drill something after the fashion of the "drilling jars" used in our oil and gas fields. It supplements the hammer blow of the drill and, also, helps to jerk the drill free from the rock on the upward pull of the cable. The latter is not fashioned of hemp, as one might suppose, but is made up of strands of split bamboo-commonly three of them, and this line is secured by a length of Manila rope to a hook engaging an iron eje on the short arm of the beam. The lower end of this hook has a heart-shaped grip, and every time the drill is raised the operative at the well mouth gives it a half twist, and in this manner causes each succeeding

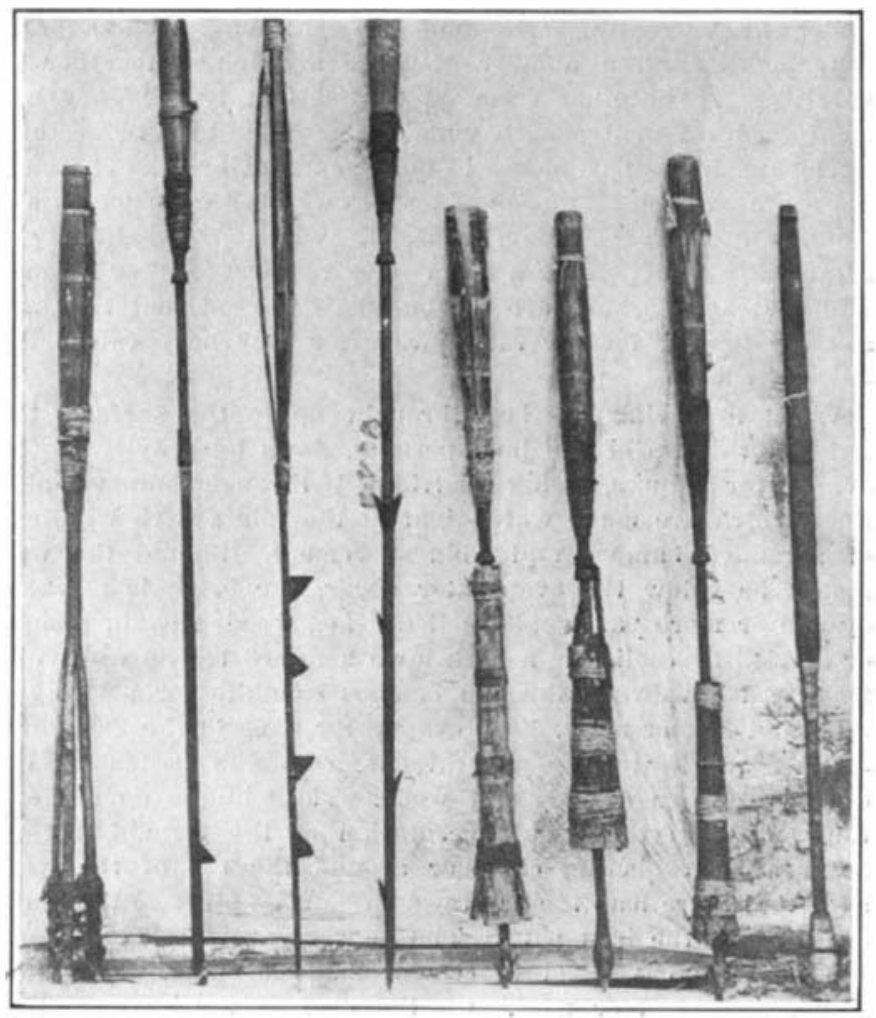

SOME OF THE PRIMITIVE TOOLS USED FOR RECOVERING LOST DRILLS, SINKER BARS, ETC.

blow of the drill to strike at a different angle. This insures the boring of a round hole and tends to make the jamming of the drill less likely.

After ten minutes of hopping on and off the "jumping beam," the coolies rest while the drill rope is being lengthened. Apparently the eight-hour-day is the rule in that section of China, because three shifts are employed to keep the work going night and day. The hole is deepened at an average rate of 3 feet every twenty-four hours. The cost of drilling a well varies according to the depth, and is said to run from $\$ 2,000$ to $\$ 17,000$. If nothing unforeseen happens to interfere with the execution of the task, it is possible to drive a 
well in from three to five zears, but this may be much prolonged by tools breaking off in the hole, by the inundation of the well by subterranean streams, and by the halting of operations through all too frequent litigation. Indeed, with these contingencies arising, the successful completion of a well may involve a period of anywhere from ten to twenty years. In a country where time counts for little this does not dismay, and it is a fact that native capitalists look with marked favor upon salt well enterprises though it may be a decade or so before anything is realized on the investment.

Should water enter from an underground source during drilling, the Orientals resort to a well-tried remedy. A plug or wad of coarse grass is forced down the bore to a point below the leak, and on top of this obstruction is poured a composition of lime, clay, and wood oil. This mixture hardens rapidly, effectually closes the water-bearing seam, and is subsequently pierced by the drill in its deeper quest for the salty store.

Chinese engineers have shown much cunning in devising tools for the recovery of drills, etc., which have been lost by the breaking of the bamboo line, and these are so patterned that they will meet successfully well-nigh every accidental condition. They range from heavily weighted spears to single and triple rods carrying one or more barbs calculated to catch some part of the lost gear and make it practicable to retrieve it.

With the well bored and the deeply-lying brine reached, then comes the problem of raising the salt-laden fluid to the ground's surface, $1,000,2,000,3,000$, or 4,000 feet above. The bailers are formed of sections of bamboo having a diameter of four inches, and a number of these are joined together to constitute a container from 50 to 100 feet long. They are reinforced frequently with windings of wire and twine, and have capacities of from 300 to 600 pounds of brine. The bailers are drawn up by means of buffalo winches upon which are wound the bamboo-ribbon ropes to which the bailers are attached. A lift from a deep well requires ten or twenty minutes; and so hard are the buffaloes worked that they are allowed to rest for several hours after they have raised the bucket twice.

When the brine has been brought up to the surface, the fluid, if the dip of the land permits, flows by gravity to the evaporator houses, being distributed through bamboo pipe lines which are made water-tight at the joints with windings of shredded bamboo and Chinese cement. Should the well mouth be below the evaporator sheds, the brine is elevated by one or more "dragon-bone lifts," i.e., wooden chain pumps, or carried by coolies to a tank upon a raised trestle whence it may feed downward through bamboo conduits for possibly a thousand feet or more. The evaporator pans in the Szechwan district are heated by natural gas, which is frequently encountered when driving salt wells. The Chinese do not cap their wells in the usual acceptation of the term, but they build a gas-collecting chamber around the top of the well, and from there lead the gas through bamboo pipes to the burners: beneath the iron pans. The burners are formed of bamboo and are enveloped in cement made of lime, granulated tiling, and sand or mud. On the roof of the gas-collecting chamber are mounted similar burners, and these are lighted to stimulate combustion when the gas pressure rises beyond that needed to supply the evaporator jets. The Chinese do not use valves to regulate the emission of the gas, but allow it to burn steadily at all the burners when there is enough of it, and simply cover up some of these when the supply begins to wane.

It is a matter of record in the salt industry of the United States that the machinery and metal equipment deteriorate rapidly. Therefore, the Chinaman with his simple apparatus, for the most part of wood and vegetable fiber, has adopted mediums calculated to last fairly well and to be easy of replacement. However, more modern facilities are winning recognition in the Tzuliuching district, and steam hoists have gained a foothold. The first of these was introduced about 1915 , when an epidemic among the buffaloes and oxen threatened to halt activities. The steam plants are built in Hankow and Shanghai, and steel rope is sent to the salt wells from the United States. The salt is produced at a cost of about half a cent a pound, and the laborers are paid around $\$ 2.50$ a month, their food being furnished gratis.

\section{PHYSICAL PROPERTIES OF ICE}

Professor Motonori Matsuyama of the Kyoto Imperial University, Japan, publishes in the October-November number of The Journal of Geology the results of his investigations carried on at the University of Chicago on "Some Physical Properties of Ice."

In introducing his article the author says: "The motion of an ice sheet along the mountain slopes and over a large area of the continent may be caused by more or less different forces. Besides the external forces it is also important to know what is the behavior of the ice itself in such motion. Numerous works have been published on these problems, among which those of McConnell and Mügge are famous and have been referred to by many authors. According to them an ice crystal can be sheared more easily in the direction parallel to the basal plane than in any other direction."

The author's own experimental investigations covered such problems as that of the determination of the Limit of Elasticity, the Modulus of Rigidity, the Ratio of the Stress to the Strain, Torsion by Constant Force, Torsion by Increasing Force, Bending and Crystalline structure.

The author finds:

(1) In some specimens of ice a sharply defined elastic limit was noted, though in other cases it was not so clearly shown.

(2) The modulus of rigidity of ice, when the crystals are perpendicular to the axis of the test piece, is very small compared to that of metals, and is about $2 \times 10^{6}$ c.g.s. There is a slight indication that it is greater when the shearing is parallel to the base of the constituent crystals than when it is perpendicular.

(3) The Young's modulus is also very small compared to that of metals. It is largest when the crystals are parallel to the length of the test piece, and has the numerical value about $20 \times 10^{-6}$ c.g.s.

(4) Elastic fatigue was marked after repeated torsion. On account of the fact that it was often necessary to use certain bars in successive experiments during which they suffered from different amounts of fatigue, it was difficult to compare the results bearing on ice bars with crystals parallel and perpendicular to the length of the test piece. Still there were some indications that beyond the limit of elasticity the former orientation was stronger than the latter against torsion. In the case of bending experiments, this was clearly shown.

(5) The torsional deformations both by constant and by increasing forces were observed and the result is shown by curves, though no mathematical conclusions were made. The recovery curves showed that the observation was approaching the stage where no recovery would take place after removal of the force.

(6) When an ice bar with crystals parallel to its length was bent, the bent portion showed the change of optical character, the extinction swinging around the curve. In each crystal when the bent specimen consisted of parallel crystals running horizontally across it, parallel straight lines were observed.

The conclusion is reached that these facts seem to show that gliding planes parallel to the base of each crystal are not the controlling factor in the deformation of ice and probably are not even an important factor. But instead, adjustments along the contact surfaces of adjacent crystals and perhaps the development of planes of weakness in the constituent crystals parallel to their long axis seem more effective in the process of deformation. 


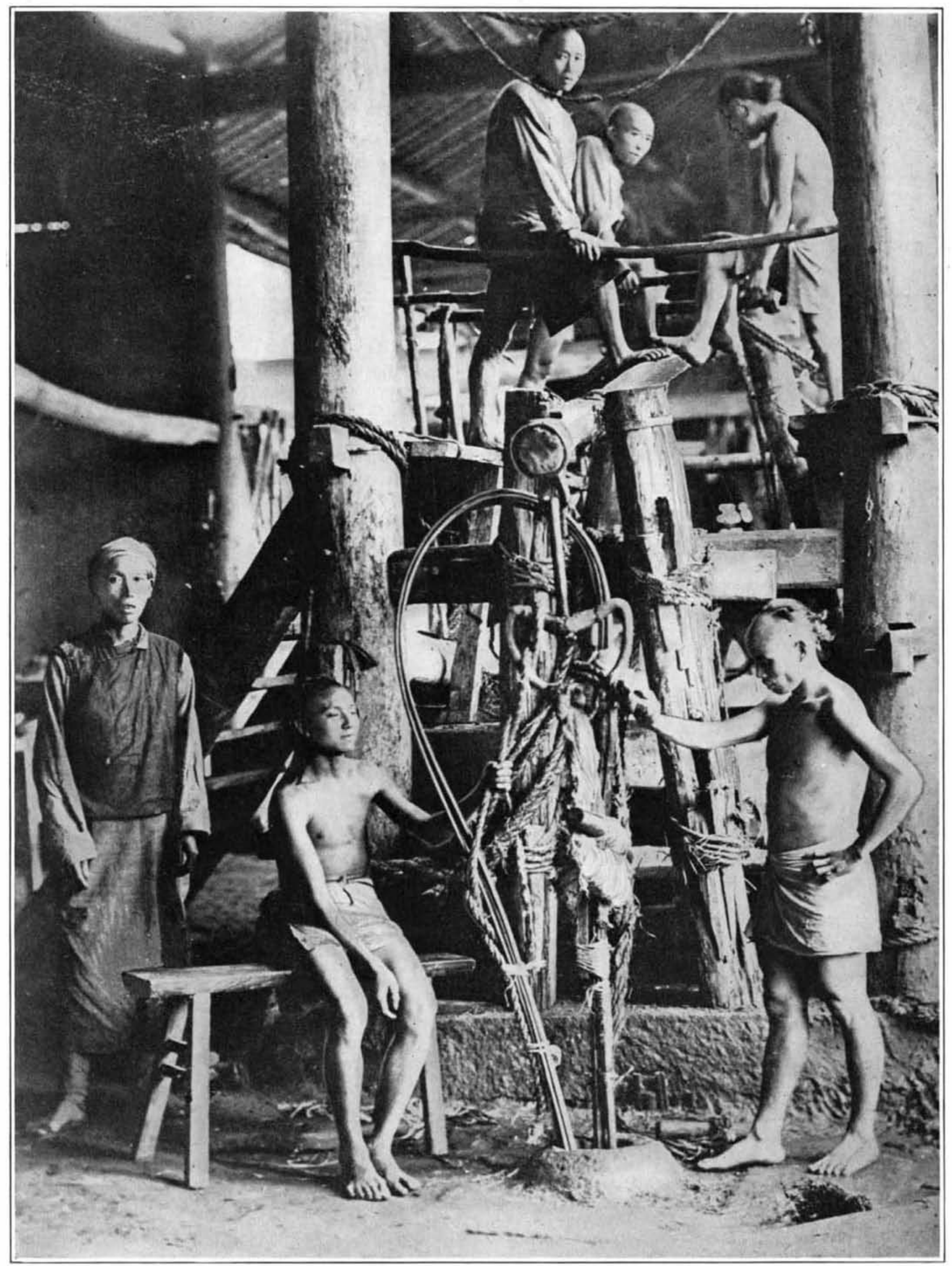

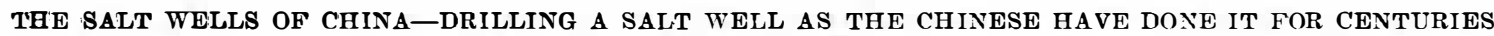

